\section{An XRF study in mechanisms of chromium removal from industrial storm water using peat medium}

BRANDY D. STEWART ${ }^{1}$, SARAH L NICHOLAS ${ }^{2}$, PAUL EGER $^{3}$, CODY SHEIK $^{4}$ AND BRANDY M TONER ${ }^{1}$

${ }^{1}$ University of Minnesota

${ }^{2}$ Brookhaven National Laboratory

${ }^{3}$ Global Minerals Engineering

${ }^{4}$ University of Minnesota Duluth

Presenting Author: stewarb@umn.edu

Treatment processes for metals in industrial storm water can be cost prohibitive. Therefore, passive remediation strategies using natural materials and microbial processes have the potential to provide affordable solutions for removing metals from aqueous waste streams, which is important from regulatory and environmental quality perspectives. Our research explores the key chemical, biological and physical processes promoting removal of hexavalent chromium $(\mathrm{Cr})$ from an industrial storm water treatment system by association with granular organic peat media. In this installation chromium is primarily in the water soluble and carcinogenic hexavalent form, chromate. Prior to treatment, chromate is converted to $\mathrm{Cr}$ (III) via an oxidationreduction reaction using iron sulfate $\left(\mathrm{Fe}(\mathrm{II}) \mathrm{SO}_{4}\right)$. The resulting $\mathrm{Cr}(\mathrm{III})$ is less water soluble than chromate ( $\mathrm{Cr}(\mathrm{VI})$, making $\mathrm{Cr}$ precipitation as hydroxides likely. The removal capacity for $\mathrm{Cr}(\mathrm{III})$ is much higher than expected for adsorption and filtration alone, suggesting other mechanisms, including microbially mediated attenuation may play a role. In addition to filtration of $\mathrm{Cr}$ (III) precipitates, the presence of excess Fe(III) (from the pretreatment step) could yield $\mathrm{Cr}(\mathrm{III})$ co-precipitation with $\mathrm{Fe}$ minerals and/or serve as a terminal electron acceptor.

Samples were collected from an industrial-sized installation in Howell, MI USA, where Cr-laden storm water is treated in large, flow-through tank reactors filled with a peat sorbent material. We sampled one reactor in four different locations at four depths for a total of 16 solid-phase peat material samples after 1 and 3.5 years. Chemical digestions show total $\mathrm{Cr}$ concentrations ranging from $400-900 \mathrm{mg} / \mathrm{kg}$ peat after 3.5 years dependent on depth and location. X-ray Fluorescence Microprobe (XFM) data reveal that $\mathrm{Cr}$ is heterogeneously distributed within the remediation media with both diffuse and "hot spot" features on the micron to $10 \mathrm{~s}$ of micron scale and is highly correlated with $\mathrm{Fe}$ and $\mathrm{Zn}$. Additionally, X-ray Absorption Near Edge Structure (XANES) results show both $\mathrm{Cr}$ (III) and metallic Cr-bearing particles in the same sample often as rind-like features accumulating on the surface of peat particles over time.
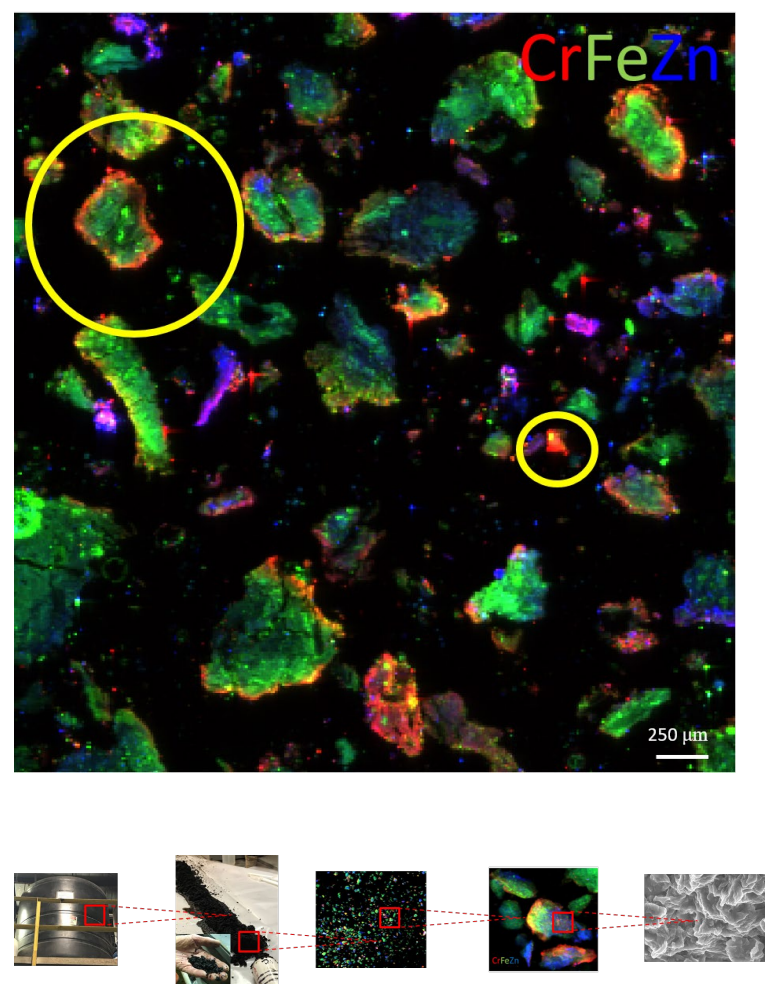